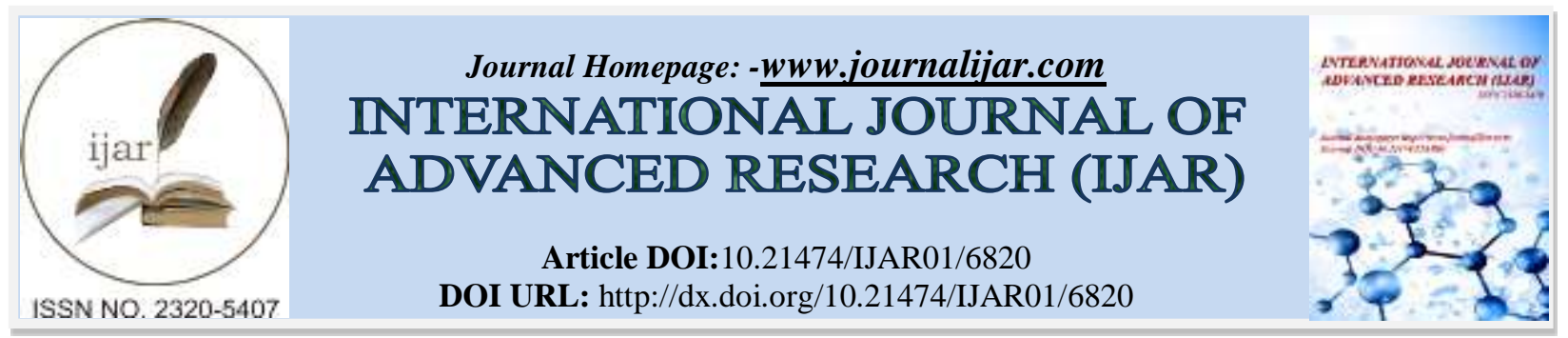

RESEARCH ARTICLE

\title{
RARE CASE OF ACUTE COMPARTMENT SYNDROME OF THE FOREARM FOLLOWING AN ELBOW DISLOCATION.
}

\section{F. Saoudi, O Benhazim, R Bassir, M Boufettal, A. Albardouni, M Kharmaz, MO Lamrani, M Ouadghiri, M Mahfoud and MS Berrada. \\ Department of Orthopaedic Surgery and Traumatology, Ibn Sina UHC, Mohamed V University, Rabat, Morocco.}

\section{Manuscript Info}

Manuscript History

Received: 02 February 2018

Final Accepted: 04 March 2018

Published: April 2018

Keywords:-

elbow, dislocation, compartment syndrome, fasciotomy.

\section{Abstract}

We report a rare case of compartment syndrome in a 29-year-old athlete following elbow dislocation. Five hours after orthopaedic reduction. Surgical decompression by fasciotomies of the volar and dorsal compartments of the forearm is performed. There was a complete disappearance of symptoms during the clinical monitoring. In conclusion, this article highlights the importance of the clinical suspicion of compartment syndrome following a dislocation of the elbow, which is often underestimated.

Copy Right, IJAR, 2018,. All rights reserved.

\section{Introduction:-}

The acute compartment syndrome is a hyper-pressure in one or more muscle compartments secondary most often to trauma [1]. This is a surgical emergency, fasciotomy is the only way to decompress the compartment concerned which decided on clinical signs and measurement of intramuscular pressure [2,3]. In the absence of early decompression, sequelae can be severe including amputation. We report here a rare case of acute compartment syndrome of the forearm following dislocation of the elbow in a young athlete.

\section{Case Report:-}

A 29-year-old footballer arrives in emergency room for acute dislocation of the left elbow. Examination at admission does not find any vascular or nervous disturbances [Fig 1 and 2].
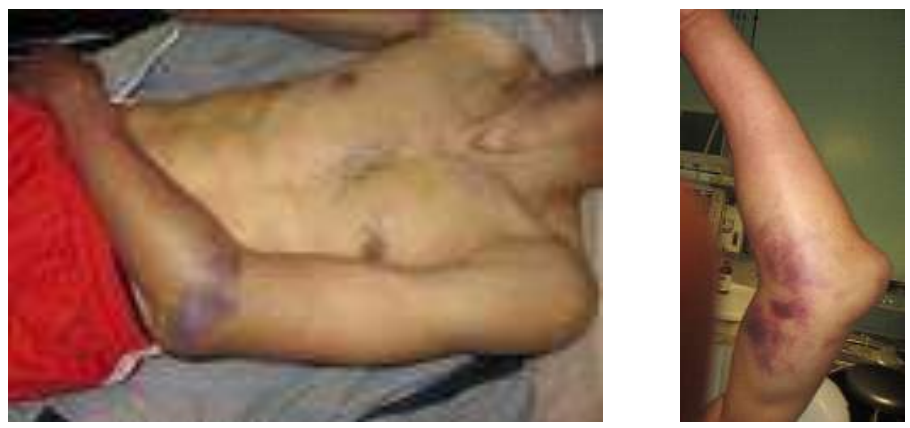

Figure 1a; b:- Clinical aspect of elbow dislocation.

Corresponding Author:- F. Saoudi.

Address:- Department of Orthopedic Surgery and Traumatology, Ibn Sina UHC, Mohamed V University, 


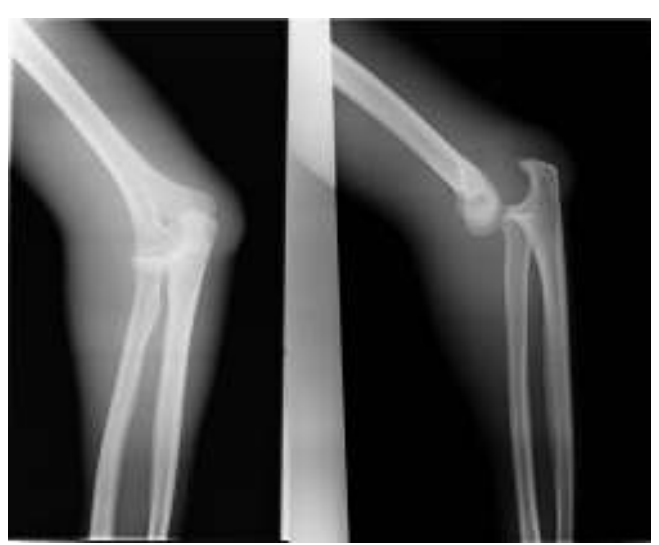

Figure 2:- Pure postero-external dislocation of the elbow on standard radiography

The dislocation was reduced under sedation and immobilized in a splint. Five hours later, the patient returns to the emergency room, this time for significant pain and swelling of the forearm and hand with partial sensory-motor deficiency of the radial nerve and median nerve [Fig 3].
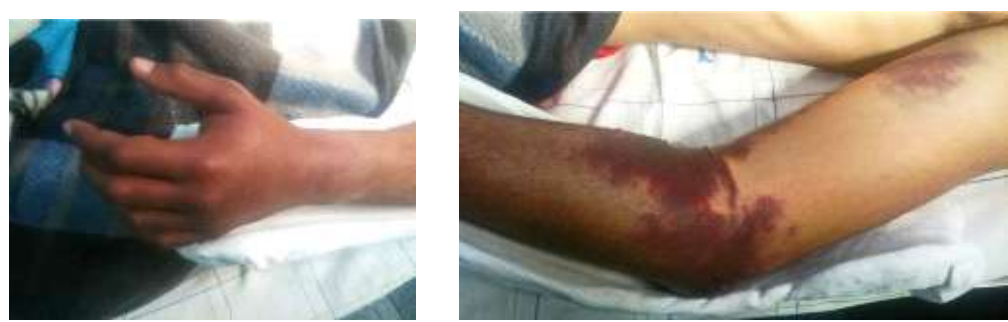

Figure 3a; b:- Clinical aspect of the forearm five hours after the reduction of elbow dislocation

The diagnosis of compartment syndrome is based on the neurological signs and the pain resistant to the strong analgesics. Emergency surgical decompression was performed by fasciotomies of the volar and dorsal compartments of the forearm. An incision extending from the biceps tendon to the palm of the hand, without decompression of the canal. An extensor compartment release was also performed through a direct dorsal incision [fig 4].
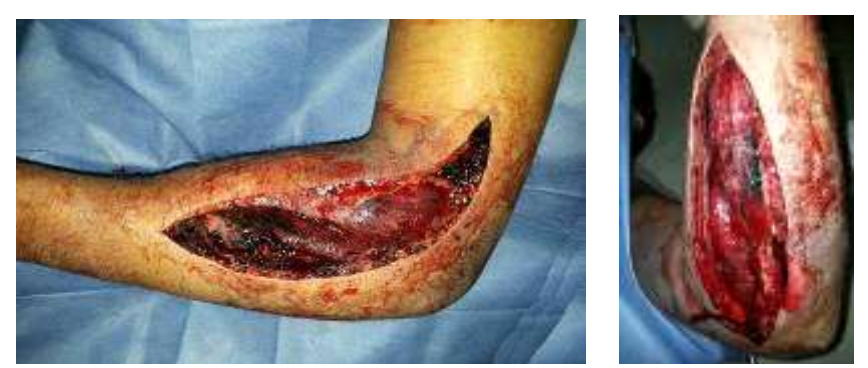

Figure 4a; b:- Decompression fasciotomies of the ventral and dorsal forearm compartments.

The fascial incisions allowed us to make a complete inspection of the muscles of all compartments to check their viability. The forearm was immobilized in a splint. Fasciotomy wounds were covered with a fatty dressing. Recovery of fasciotomy wounds was performed after 48 hours with a nearing of the wound edges, a complete controlled wound healing was obtained after eight weeks without functional sequels.

There was a complete disappearance of the pre-operative symptoms during intra-hospital monitoring. The follow-up period was twenty-four months the patient was very satisfied both aesthetically and functionally.

\section{Discussion:-}

The acute compartment syndrome is rarely associated with pure dislocation of the elbow [4]. A combination of clinical signs and compartment pressure monitoring is often required to make a diagnosis of forearm compartment 
syndrome, a recent review finding that monitoring of the forearm is only used approximately 50\% of the times $[1,2,4]$. It is also important to note that presentations of compartment syndrome are not always acute, but may be sub-acute and at times chronic [5]. Overall, the typical patient at risk of making an acute compartment syndrome is a man younger than 35 years and has been involved in a high energy sport or traffic collision $[6,7]$.

The fasciotomy can be performed at the latest within the first 6 hours, either due to a clinically obvious case of syndrome and / or to the results of compartment pressure measurements [8]. The fasciotomies incisions must be large enough to adequately decompress affected compartments [5].

Although there is no consensus regarding the optimum timing of wound closure [9], several authors advocate a closure delayed after seven days which allows wound edges approximation at closure [10]. Some techniques developed can facilitate skin closure such as vacuum-assisted closure and shoelace suturing techniques [9].

\section{Conclusion:-}

The compartment syndrome can express itself clinically in various aspects. In the absence of early decompression, sequelae can be very important and irreversible, including amputation.

This work highlights the importance of clinical monitoring of any reduced elbow dislocation for a few hours even if no clear vascular disruptions are presents, which is not done often enough in our current practice.

\section{References:-}

1. Holden CE. Compartmental syndrome following trauma. Clin Orthop 1975;113:95-102.

2. Letenneur J, Arnaud JP, Frieh JM, Meynet JC, Oudet D, Rogez JM, et al. Syndrome des loges des membres inférieurs, Table ronde. Société Orthopédique de l'Ouest, juin 1988. Ann Orthop Ouest 1989;21:155-88

3. Letenneur J. Syndromes loges de jambe. In: Conférence d'enseignement de la SOFCOT. Cahiers d'enseignement. Paris: Expansion Scientifique Française; 1999. p. 185-98 (nº70).

4. Queipo-de-Llano Temboury A1, Lara JM, Fernadez-de-Rota A, Queipo-de-Llano E.

5. Anterior elbow dislocation with potential compartment syndrome: a case report. Tech Hand Up Extrem Surg. 2007 Mar;11(1):18-23.

6. Nigel Tapiwa Mabvuure, Marco Malahias, Sandip Hindocha, Wasim Khan, and Ali Juma. Acute Compartment Syndrome of the Limbs: Current Concepts and Management. Open Orthop J. 2012; 6: 535-543.

7. Taylor RM, Sullivan MP, Mehta S. Acute compartment syndrome: obtaining diagnosis, providing treatment, and minimizing medicolegal risk. Curr Rev Musculoskelet Med. 2012;5(3 ):206-13.

8. McQueen MM, Gaston P, Court-Brown CM. Acute compartment syndrome. Who is at risk? J Bone Joint Surg Br. 2000;82(2 ):200-3.

9. J. Letenneur, G. Pietu : Syndromes des loges. 15-110-A-10 2005 Elsevier SAS.CHU de Nantes, France

10. Gourgiotis S, Villias C, Germanos S, Foukas A, Ridolfini MP. Acute limb compartment syndrome: a review. J Surg Educ. 2007;64(3):178-86.

11. Ojike NI, Roberts CS, Giannoudis PV. Compartment syndrome of the thigh: a systematic review. Injury. 2010;41(2 ):133-6. 